\title{
O éthos na economia da teoria semiótica
}

\author{
Francisco Elias Simão MERÇON (Universidade de São Paulo)
}

RESUMO: Uma das vias de aproximação da retórica à semiótica é aquela que integra a noção de éthos na relação de manipulação entre os actantes narrativos e no processo de figurativização dos atores. Para ilustrar tal propósito, iremos nos valer de um trecho da novela A Metamorfose, do escritor Franz Kafka.

PALAVRAS-CHAVE: éthos; habitus; semiótica; retórica; Franz Kafka

\begin{abstract}
A way to approximate Rhetoric to Semiotics is that one that integrates the rhetorical notion of ethos in the persuasive process which involves narrative actants and also in the process of figurativization involving actors. In order to demonstrate this aspiration, we will analyse a part of Kafka's work The Metamorphosis.
\end{abstract}

KEYWORDS: ethos; habitus; semiotics; rhetorics; Franz Kafka 


\section{Introdução}

O presente estudo teve início a partir da leitura da novela A Metamorfose (KAFKA, 1997), do escritor tcheco Franz Kafka, que, por sua vez, constitui o corpus de minha pesquisa de mestrado. Mais exatamente, as questões em torno da noção de éthos, sobre as quais me debrucei durante a análise da novela de Kafka, são questões envolvendo sobretudo a personagem Grete, irmã do protagonista Gregor Samsa. O objetivo aqui é observar o desenvolvimento dessa personagem, que, no final da terceira e última parte da novela, exerce um papel decisivo no destino do irmão Gregor. Antes, porém, de entrar diretamente na questão, façamos um breve resumo da novela e sua relação com o trecho em que a discussão do éthos adquire sua pertinência.

\section{A metamorfose de Gregor e o ambiente familiar}

A novela A Metamorfose nos apresenta a história do cotidiano de uma família (a família Samsa), que tem um de seus integrantes (o filho Gregor Samsa) transformado repentinamente em um inseto. Após a metamorfose de Gregor, a família Samsa passa a ter que conviver forçosamente com um ser ambíguo, ainda humano, mas já inseto. Como se isso não bastasse, a situação financeira dos Samsa - que já não gozavam mais da estabilidade vivida antes da falência do pai - sofre um segundo declínio, visto ter sido Gregor até então o único responsável pelo sustento da família.

Diante desse quadro disfórico de sucessivas descontinuidades, que podem culminar na total disjunção da família Samsa com tudo aquilo que representara até então valores como conforto, harmonia, tranqüilidade, etc., cada um dos integrantes da família Samsa - à exceção de Gregor - assume um trabalho, com o objetivo de garantirlhes o sustento, e quem sabe, assim, restaurar a estabilidade no ambiente familiar.

De certa forma ainda insuficiente o empenho de cada um na tentativa de proteger a família de uma iminente desgraça, um dos cômodos da casa, o quarto de Grete, irmã de Gregor, é alugado a três estranhos inquilinos, cuja presença, por sua vez, exige da mãe e da filha esforços dobrados nos trabalhos de casa. Além do que, desde então já não contam mais com a presença da cozinheira. Somados todos esses infortúnios e sujeição a uma situação deplorável para uma família que provavelmente deve ter vivido seus momentos de glória, o quadro que se tem ainda inclui a presença, no ambiente familiar, de um ser repugnante, que, por sua vez, exige cuidados especiais, assim como prescreve o "mandamento do dever familiar", quando um mal acomete a um membro da família.

Nesse sentido, apesar de todos os esforços da família para recuperar o estado de plenitude que vivera outrora, o que se pode perceber é que o ambiente familiar é tomado por um crescente estado de tensão, decorrente sobretudo da presença cada vez mais intensa do ser repugnante que se torna Gregor após a metamorfose. A situação só não nos parece pior, porque a história é contada sob o ponto de vista de Gregor, que na maior parte se mostra quase que totalmente impassível diante de toda a situação. Em todo caso, Gregor não parece ser afetado por nenhuma paixão forte, com grande intensidade. Além do mais, suas competências se exauriram após sua transformação em inseto. Por exemplo, seu saber fica limitado, temporalmente, às lembranças do passado 
e, espacialmente, àquilo que ele pode perceber em seu horizonte, ou seja, o espaço fechado de seu quarto.

\section{A metamorfose de Grete}

Apresentado o quadro geral do cotidiano da família Samsa depois da transformação de Gregor em um inseto, fica indubitável a condição de anti-sujeito de Gregor, sobre quem recaem as causas da deplorável situação na qual se encontra a família. Ele não só não possui mais a competência que lhe era exigida no contrato familiar, como também passa a colocar em risco a competência de seus familiares e, por conseguinte, seu estado de plenitude. Em outras palavras, se Gregor até então tinha um espaço reservado na composição da família, ainda que restrito ao espaço excluso de seu quarto, sua condição de anti-sujeito passa a ameaçar a instituição familiar e, portanto, torna-se imprescindível seu total afastamento.

Vejamos então um pequeno trecho em que é dado o veredicto final no destino de Gregor, antes de iniciarmos as questões acerca do éthos:

— Queridos pais - disse a irmã e como introdução bateu com a mão na mesa -, assim não pode continuar. Se vocês acaso não compreendem, eu compreendo. Não quero pronunciar o nome do meu irmão diante desse monstro e por isso digo apenas o seguinte: precisamos tentar nos livrar dele. Procuramos fazer o que é humanamente possível para tratá-lo e suportá-lo e acredito que ninguém pode nos fazer a menor censura (KAFKA, 1997: 74).

Para a surpresa de Gregor, e certamente do leitor, é a dedicada irmã que se encontra agora na condição de destinador julgador, a mesma que durante todo o momento que sucedera a metamorfose assumira os cuidados para com ele, Gregor. A questão que se impõe é, portanto, a seguinte: como é possível que Grete, que até então parecera aos olhos da família "uma moça algo inútil", passe a responder em nome de uma justiça cujo poder exerce a implacável sanção em Gregor? O que é responsável pela transformação da competência modal de Grete, que a princípio se mostra como um sujeito incompetente (ou seja, um sujeito que não sabe e nem pode fazer nada), e de súbito se apresenta dotado de saber e poder absolutos?

\section{4. Éthos, habitus e ética}

Essas questões adquirem sua maior pertinência por serem pensadas no âmbito familiar, em que a constituição do actante coletivo "família" envolve papéis temáticos e actanciais específicos para cada um dos participantes familiares. Creio que uma resposta possível às duas questões postas anteriormente reside em torno da noção de éthos, em sua relação com a ética e com a noção sociológica de habitus, de Pierre Bourdieu, incorporada por Dominique Maingueneau em seus estudos de análise do discurso. $\mathrm{O}$ que tentaremos mostrar é que ambas aproximações feitas à noção de éthos parecem apropriadas sem maiores problemas à economia da teoria semiótica. Assim como faz Maingueneau (2004), um dos nossos objetivos é fazer transitar a noção de éthos entre 
sua tendência persuasiva e sua tendência sensível que nos remete, por sua vez, a um corpo encarnado e historicamente marcado.

Vejamos, primeiramente, uma passagem da Retórica de Aristóteles, em que ele tece algumas considerações que vão nos servir de baliza para as que virão a seguir:

Obtém-se a persuasão por efeito do caráter [éthos] moral, quando o discurso procede de maneira que deixa a impressão de o orador ser digno de confiança. As pessoas de bem inspiram confiança mais eficazmente e mais rapidamente em todos os assuntos, de um modo geral (ARISTÓTELES, 1959: 24).

Aqui, é explícita, nas palavras de Aristóteles, a tendência persuasiva da noção de éthos. De fato, o fazer persuasivo do orador (ou enunciador) depende de sua competência discursiva e do caráter que o torna "digno de confiança". Em outras palavras, para obter o sucesso na persuasão - ou seja, a adesão do enunciatário - o enunciador tem que necessariamente ser o fiador de seu próprio discurso. Nesse sentido, há uma passagem da novela A Metamorfose, em que a narrativa nos informa que Grete, tal qual o orador que é "digno de confiança", passa a inspirar a confiança dos pais, mediante a imagem que criara de si ao assumir integralmente os cuidados para com o irmão:

Nas duas primeiras semanas [depois da metamorfose] os pais não conseguiam vencer a própria resistência para entrar no quarto [de Gregor] e vê-lo, e com freqüência ele [Gregor] ouvia como reconheciam plenamente o trabalho da irmã, ao passo que até então tinham muitas vezes se irritado com ela, porque lhes parecera uma moça algo inútil. Mas agora ambos, pai e mãe, aguardavam diante do quarto de Gregor enquanto a irmã fazia a arrumação, e mal ela tinha saído, precisava contar exatamente como estavam as coisas no quarto, o que Gregor havia comido, como se comportara dessa vez, e se por acaso era possível notar uma pequena melhora (KAFKA, 1997: 46-47).

Nota-se que o trecho citado não nos fornece o discurso proferido por Grete, relatando aos pais o estado do irmão, mas não podemos deixar de considerar uma suposta eficácia de suas palavras mediante a confiança conquistada nos assuntos acerca do irmão, fato que pode ser confirmado no momento em que mãe e irmã decidem retirar alguns móveis do quarto de Gregor, para lhe dar mais espaço. Conforme o trecho mencionado, a irmã passou a "se apresentar diante dos pais, nas conversas sobre as questões de Gregor, como perita (...)” (KAFKA, 1997: 50).

Fica claro, então, desse modo, que não bastava à irmã de Gregor dizer ser competente para assumir os cuidados do irmão, mas, sobretudo, dadas as circunstâncias em que se encontrava no espaço hierárquico da família, muito mais do que dizer, ela soube mostrar sua competência no seu modo de agir.

Além da tendência persuasiva verificada na concepção aristotélica de éthos, vejamos um outro importante elemento a ser ressaltado. Trata-se da expressão empregada pelo estagirita: "pessoas de bem". Provavelmente Aristóteles aqui se refere às suas concepções morais desenvolvidas posteriormente de maneira minuciosa em sua obra Ética a Nicômaco (2002), para a qual o fim último do homem é o bem. Mas o que de fato importa para nossa abordagem é que o "bem" de que fala Aristóteles é um valor 
que molda todo um comportamento do homem mediante prescrições e interdições, ou o que podemos resumir na noção de ética.

Ao considerar a ética na relação interpessoal, pensamos que essa não determina apenas aquilo que pode ser dito, mas também o modo como algo deve ser dito. Por outro lado, trata-se de não instaurar uma ruptura entre o modo de dizer e o modo de agir, visto que o éthos, como bem salienta Maingueneau, "aparece indissociável de uma 'arte de viver', de uma 'maneira global de agir', daquilo que um sociólogo como Pierre Bourdieu denomina habitus" (MAINGUENEAU, 2004: 214).

Nesse sentido, consideradas essas observações, podemos distinguir o comportamento assumido por Grete, a irmã de Gregor, como um compromisso, dado seu empenho em lidar com irmão que necessita de cuidados especiais. Com efeito, é ela quem se responsabiliza pela alimentação de Gregor, pela limpeza de seu quarto, pela alteração da disposição dos móveis no quarto de Gregor. Na verdade, a condição em que se encontrava a família Samsa depois da metamorfose leva pai, mãe e filha a adotar essa maneira de agir. Ou seja, trata-se de um modo de agir compartilhado por todos, à exceção de Gregor, que permanece indiferente em seu quarto, impotente devido à sua condição de inseto.

Vê-se, portanto, que há um habitus, um modo de agir da família Samsa, ao qual adere Grete, decorrente de uma ética que determina tanto o valor quanto as prescrições e as interdições no círculo familiar dos Samsa. A novela A Metamorfose parece, portanto, encenar em meio à sua trama, um julgamento ético que divide os modos de agir da família Samsa, entre, de um lado, pai, mãe e filha, estes agindo com compromisso, e de outro, Gregor, que age com indiferença.

\section{Conclusão}

Podemos, então, dizer que Grete, ao assumir determinado éthos, mostra compreender e assimilar o habitus, a ética, perante os valores que fazem parte de sua família, para, somente assim adquirir a competência necessária de sujeito persuasivo. Com isso, opera-se a transformação de sua simples condição de sujeito, participante do actante coletivo "família", para a condição de destinador julgador, a partir da qual vê-se exercer o poder sobre o destino de Gregor.

Estaríamos, assim, diante de um caso de mimetismo semiótico, tal qual ocorre no mundo animal, em que uma simples mudança figurativa pode ser fatal, na medida em que freqüentemente inverte as posições na relação presa/predador?

\section{REFERÊNCIAS BIBLIOGRÁFICAS}

ARISTÓTELES. Arte retórica e arte poética. São Paulo: DIFEL, 1959. 335 p. . Ética a Nicômaco. São Paulo: EDIPRO, 2002. 287 p.

KAFKA, Franz. A Metamorfose. São Paulo: Companhia das Letras, 1997. 102 p.

MAINGUENEAU, Dominique. Le discours littéraire: Paratopie et scène d'énonciation. Paris: Armand Colin, 2004. 272 p. 


\section{Como citar este artigo:}

MERÇON, Francisco Elias Simão. O éthos na economia da teoria semiótica. Estudos Semióticos, Número 2, São Paulo, 2006.

Disponível em <www.fflch.usp.br/dl/semiotica/es>. Acesso em

"dia/mês/ano". 